\title{
NARRATIVA FOTOGRÁFICA EM PORTO RICO: UM OLHAR SENSÍVEL SOBRE A CULTURA BORÍCUA
}

\author{
Camila Fontoura ${ }^{1}$
}

\section{Introdução}

O presente trabalho será um relato abordando um pouco da experiência que tive desenvolvendo o meu trabalho de campo para a pesquisa da Dissertação do Mestrado, que foi realizado em Porto Rico no primeiro semestre de 2015. Devido a minha aproximação com a antropologia visual, meu objetivo (e desafio) foi a utilização da imagem - fotografia - não "apenas" como técnica de registros de dados ou meramente uma fonte/dispositivo ilustrativo, mas como outra forma de narrativa agregada à descrição textual.

Nesse sentido, o debate sobre a antropologia visual se faz necessário, pois a utilização da imagem bem como outros dispositivos visuais (fotografia, vídeo, áudio, etc.) somam-se no processo etnográfico e incorporam-se no desenvolvimento da análise juntamente com o texto na pesquisa desenvolvida. Os debates teóricos acerca da utilização da imagem e da antropologia visual são relevantes, pois estão em "disputa" no cenário das ciências sociais, visto que vertentes mais "tradicionais" da antropologia ou outras áreas do conhecimento ainda não "aceitam" ou talvez não legitimem essas outras formas de produção do conhecimento científico. Discutir, utilizar e ressaltar o potencial narrativo das imagens fotográficas é essencial, pois o cerne da questão está justamente em aclarar e revelar a inter-relação/interlocução da fotografia com o texto, uma vez que os mesmos estão imbricados no discurso analítico. Penso que como recurso, a fotografia, o uso de imagens se traduz como uma materialização do texto escrito, através de uma narrativa imagética desvelando potencialidades não escritas.

\footnotetext{
${ }^{1}$ Pontifícia Universidade Católica do Rio Grande do Sul, Brasil.
} 


\section{Algumas considerações sobre a Antropologia Visual}

Ao se buscar um "marco" para o que descreveria o inicio de, para o campo científico, a antropologia visual - como disciplina, ferramenta e meio de produção de conhecimento - é geralmente citamos Margaret Mead. A intelectual foi uma das primeiras em chamar a atenção para utilização de imagens e outras tecnologias como outra forma de narrativa no discurso analítico além da discrição textual.

Mead (1979) aborda sobre a questão do trabalho de campo e suas dificuldades, como por exemplo, de clima e condições difíceis e adversas. Assim, surge a necessidade de usar as tecnologias em favor do pesquisador, por conseguinte, afirma que:

[...] anthropologue s'empresse d'utiliser dans son domaine des méthodes nouvelles qui simplifieraient ou amélioreraient son travail de terrain. De même que les méthodes de datation devinrent profitables aux archéologues, le phonographe, la radio, le magnétophone aux musicologues et aux linguistes, de même la photographie, le film et la vidéographie devraient l'être aux ethnologues. Les bonds fantastiques accomplis dans chaque domaine grâce à l'emploi de techniques nouvelles sont si concluants (ainsi le carbone 14 remplaça la dendrochronologie, le magnétophone le rouleau de cire, la caméra synchrone l'appareil à plaques photographiques. (Mead 1979: 13)

Em relação aos métodos e ferramentas utilizadas pelo antropólogo em sua etnografia, Mead ressalta, além da fotografia, a importância fílmica, bem como, das dificuldades e esforços para conseguir fundos para o desenvolvimento desse tipo de trabalho. Conforme cita sobre os filmes etnográficos, estes, já estavam sendo explorados, como por exemplo, por Gregory Bateson, John Marshall, e mais contemporâneos como Jean Rouch, (e mesmo a própria Margaret Mead que "militava" sobre essa questão). Mediante a esse cenário, Mead questiona porquê havia essa resistência ao cinema etnográfico, a posição e a insistência em l'on continue à prendre des notes. Qual seria o problema? Conforme descreve, uma das questões seria a fixação para as descrições verbais, e, em meio a trabalhos em ambientes de transformação rápida, o antropólogo contava apenas com a memória de seus informantes.

Nessa lógica, Mead (1979) afirma que, com os dados visuais e auditivos anotados, armazenados e reprodutíveis, nós podemos analisar outras vezes cuidadosamente a mesma informação. Bem como, instrumentos para maior precisão que enriquecem nosso conhecimento do universo, e uma melhor maneira de preservar estes documentos culturais preciosos que podem informar o nosso conhecimento e 
valorização da humanidade. Sendo assim, ressalto a importância da autora que "alertava" sobre as possibilidades e a necessidade da criação de um desdobramento da antropologia que desenvolva as potencialidades e tipos de discursos com diferentes mídias e ferramentas imagéticas na esfera das ciências sociais e principalmente da antropologia.

Uma das vicissitudes que se trava na discussão sobre a antropologia visual, por parte de um setor mais "tradicional" da antropologia, versa sobre a ideia de que tais mídias e técnicas "substituiriam" o texto. Já é sabido que a antropologia visual agrega e traz novas possibilidades para o campo cientifico, sem renunciar o discurso escrito. Apoiando-me sobre o trabalho de Etienne Samain - "Ver" e "dizer" na tradição etnográfica: Bronislaw Malinowski e a fotografia - trago algumas perspectivas com as quais me identifico, buscando no "pioneiro" Malinowski, como o mesmo vem a acrescentar para o debate da antropologia visual.

Samain (1995) disserta sobre certas questões procurando delinear alguns caminhos críticos referentes aos usos das imagens (fotográficas em especial) no campo das ciências humanas, focando no papel desempenhado pela fotografia nas obras clássicas que Malinowiski - como o antropólogo encarava a fotografia, bem como, o lugar que alocava e, a que funções a destinava dentro de seu próprio discurso antropológico.

A utilização da imagem pura e simplesmente ilustrativa não tem por objetivo em seu uso no trabalho científico para a antropologia visual. Ter o registro fotográfico, por exemplo, para "provar" que o antropólogo realizou seu trabalho de campo limita o uso e as potencialidades que a imagem pode revelar mediante as interpretações e as perspectivas que a mesma sucinta. Dizer que a fotografia pode ser "muito subjetiva", não condiz para seu possível rechaço, ora, o texto escrito não é subjetivo?

Conforme Samain reconhece, provavelmente por mais algumas décadas persistirão reservas levantadas pela antropologia clássica em relação à criação de uma antropologia visual, cita que, “já há 20 anos, Margaret Mead denunciava esse 'esmagador parti-pris verbal da antropologia' e a fixação devota - para não dizer fetichista - que esta consagrava às virtudes da escrita" (Samain, 1995: 24). O autor alerta sobre dois pontos convergentes nesse diálogo, por um lado há os pesquisadores que não tem uma formação consistente na área da antropologia e se arriscam na antropologia visual, em contra partida, há antropólogos que possuem uma formação sólida, mas que enjeitam a fundação de uma antropologia visual. 
Nesse sentido, busco sempre reforçar que o que está em "disputa" é a consolidação, ou melhor, legitimação de um campo que - atualmente está mais estabelecido - no entanto, ainda produz "ressalvas" na esfera das ciências sociais. Por conseguinte, não devemos observar sobre o prisma de um "cabo de guerra" no qual um lado necessita "vencer" o outro, assim como não se superestima a imagem ou mídias visuais, tampouco se desmerece a escrita. A antropologia visual não intui a supressão do texto escrito, e sim, que ambos os modelos, formas, ferramentas de análise coexistam, e possam estar imbricados, trabalhando em conjunto.

Em contraposição, explorando outras maneiras de apropriar-se da imagem, seus usos e funções, trago o contemporâneo Luis Eduardo Robinson Achutti - antropólogo e fotógrafo, atualmente professor na Universidade Federal do Rio Grande do Sul (UFRGS) - que nos brinda com a fotoetnografia, levando a outro "extremo" a questão das formas e usos da imagem, o mesmo evidencia a utilização da fotografia sem recurso escrito, de forma sequencial, como uma narrativa fotográfica. Em sua pesquisa de Doutorado realizada na Biblioteca Jardim, localizada na França Achutti faz um lindo e importante trabalho utilizando a Fotoetnografia como metodologia. Conforme cita,

\begin{abstract}
Uma narrativa fotoetnográfica deve se apresentar na forma de uma série de fotos que estejam relacionadas entre si e que componham uma sequência de informações visuais. Série de fotos que deve se oferecer apenas ao olhar, sem nenhum texto intercalado a desviar a atenção do leitor/espectador. Essa preocupação não impede que certas informações escritas possam ter sido anteriormente dadas àqueles que vão mergulhar na narrativa visual, isto é, a justaposição dessas duas formas narrativas é possível e mesmo desejável, mas é importante notar que o ideal seria que cada tipo de escritura fosse oferecido ao leitor separadamente, de forma que cada uma conservasse todo o seu potencial. (Achutti, 2004: 109)
\end{abstract}

A fotografia segundo Achutti é a "materialização de um olhar", o "discurso de um olhar" (Achutti, 1997: 11), nesse sentido, o potencial atribuído à fotografia reflete na importância da mesma e sua pluralidade - como ferramenta, método, discurso, etc.

Sendo assim, após citar alguns exemplos e usos da utilização da imagem no trabalho científico e algumas perspectivas sobre a antropologia visual, descrevo minimamente como foi meu processo no trabalho de campo, focando na dinâmica sobre a captação/registros fotográficos, das dificuldades, e como se deu esse processo. 


\section{Etnografando em Porto Rico}

Devido à experiência de intercâmbio que realizei no primeiro semestre de 2013, no qual cursei um semestre na Pontifícia Universidad Católica de Puerto Rico (no sétimo semestre de minha graduação em Ciências Sociais), tive a oportunidade de não só cursar disciplinas, como também realizar uma etnografia, pesquisa esta, que resultou na minha monografia de trabalho de conclusão de curso. A mesma consistia, em linhas gerais, abordar a questão da identidade cultural focada na juventude porto-riquenha.

A oportunidade de imergir por seis meses em uma cultura diferente, interatuar, conhecer, vivenciar aspectos e observar as relações das pessoas (no meu caso, jovens universitários, com as quais interagi), foi o que me impulsionou na busca de tentar compreender como aqueles sujeitos entendiam quem eram, e como se viam culturalmente. Pois, Porto Rico é uma ilha que foi duplamente colonizada, primeiramente pela Espanha do século XVI até o final do século XIX, e depois torna-se um território não incorporado dos Estados Unidos, e atualmente segue sobre a soberania estadunidense, e, portanto, não é um país independente.

A partir desse primeiro processo, a vontade de prosseguir com a análise e aprofundar esse estudo, me levaram a dar seguimento à pesquisa, agora no Mestrado. Sigo trabalhando sobre a questão da identidade cultural em Porto Rico, porém, em outra cidade com outros sujeitos. Na busca de vivenciar e conhecer uma realidade distinta da ilha, decidi realizar meu trabalho de campo em uma área mais periférica da capital, na qual se concentram comunidades e habitações populares. Meu objetivo se encaminhou em analisar outras dinâmicas, relações e percepções de outros sujeitos, num contexto diferente do anterior pesquisado.

Dito isso, trago um pouco sobre minha "aventura" pela ilha e com a fotografia. Primeiramente, creio que devo citar sobre a importância de conhecer seu equipamento. A câmera fotográfica que utilizei na etnografia era uma aquisição nova, nunca havia manuseado uma câmera profissional anteriormente. Assim, meu primeiro desafio era conhecê-la e minimamente saber pelo menos, das principais ferramentas, e o básico para utilizá-la de maneira menos "neófita", pois almejava um trabalho bem feito e de qualidade, dentro das minhas limitações. 
Já havia cursado a disciplina de Antropologia Visual e de Fotoetnografia no PPGAS (Programa de Pós-graduação em Antropologia Social na Universidade Federal do Rio Grande do Sul), mas ainda tudo incipiente pra mim no sentido prático, o teórico já estava um pouco mais internalizado, talvez. Agora era questão de por em prática e aquele meu olhar em campo e tentar "passar para os dedos" na hora do clic.

Fiz algumas "aulas" por Skype com minha irmã fotógrafa e comecei a testar a câmera, "brincar", errar muito, passar trabalho com foco, abertura, luz, trocas de ambiente, o trabalho que tinha de "arrumar" a câmera para tal local, depois mover-me e dar-me conta que estava num lugar com mais luz, por exemplo, e as fotos ficarem super claras. Enfim, passado esse "sufoco" inicial, já realizava meu trabalho de campo, porém fazia mais observações e não levava a câmera comigo, ainda não me sentia segura, pois pensava que ia "assustar" as pessoas chegando com aquela câmera grande, ou não saberia como me colocar, ou me aproximar dos lugares sabendo que eu não era invisível.

Nas minhas primeiras saídas com a câmera, fui a lugares estratégicos (céu aberto, bairros conhecidos, zonas mais turísticas, praças, parques, onde havia muito fluxo de pessoas, etc.) creio que para a visão dos "outros" eu era mais uma turista registrando as belezas da cidade. Pra mim, uma pesquisadora saindo da zona de conforto e explorando os lugares e os vínculos das pessoas para com os mesmos. A facilidade do zoom da câmera, e ser vista como uma turista me possibilitaram a estar, não necessariamente próximo das pessoas na hora do clic (no sentido de distância física), mas busquei estar sempre consciente, presente e observando muito as dinâmicas da rua, das pessoas, as relações entre as mesmas, as relações delas com os espaços públicos, etc. Pois, segundo Ana Luiza Rocha e Cornelia Eckert (2003), para antropólogo urbano, o pesquisador é como mais um habitante do espaço urbano investigado. Ou seja, tive que me "soltar" e adentrar cada vez mais no meu campo sem aquele "distanciamento" que algumas linhas epistemológicas creem ser importante.

Dando continuidade, nesse processo ainda "briguei" muito com a câmera, nem sempre conseguia me acertar, mas aos poucos foi melhorando ao longo da pesquisa. Claro, ainda sim é difícil, pois há momentos que por frações de segundos perdemos uma “cena", essas trocas rápidas de ambiente, os ajustes necessários na câmera e/ou troca de lentes, me atrapalhavam muitas vezes, pois as coisas fluem e podem fluir rapidamente no sentido espaço-tempo. Nem sempre conseguimos registrar alguns momentos 
interessantes, ou quando somos surpreendidos, tudo isso fui aprendendo pouco a pouco em medida que saía para "etnografar".

Houve momentos distintos e maneiras distintas nas aproximações com as pessoas. Um exemplo foi no mercado público da capital San Juan (no bairro Santurce), como era um lugar fechado e não muito grande, teria um contato bem próximo com as pessoas, assim para os registros das bancas e das pessoas que ali estavam, pedi o consentimento das mesmas para fazer os registros. Nesse sentido, conversei, falei rapidamente que era brasileira, que estava realizando uma pesquisa sobre a identidade cultural do país e que precisava fazer registros fotográficos. Prontamente tive a aceitação das pessoas, fui muito bem recebida de modo geral, as pessoas eram bem simpáticas comigo. Um dos donos de uma banca disse que estava acostumado a chegar "gente da TV" que muitas vezes faziam fotos e vídeos no mercado. No fim das contas, conheci os trabalhadores das bancas, pessoas que compravam, outras que paravam para tomar um suco, outras relaxavam em seu intervalo no banco da frente do mercado, e assim ouvi muitos relatos de pessoas mais velhas sobre a cultura boricua ${ }^{2}$ e suas experiências.

Outro exemplo foi no bairro específico que trabalhei maiormente para minha pesquisa, no qual ia com frequência e participava das atividades do centro cultural da comunidade. O processo aproximação foi aos poucos, fui conhecendo a comunidade, as pessoas, o centro de atividades, fui sendo vista, reconhecida e "aceita" pelas pessoas que viviam naquela localidade. Depois do primeiro mês frequentando o bairro, comecei a levar a câmera e, inclusive, participei de uma oficina sobre fotografia realizada durante um mês no centro cultural. Passei então a ser a "fotógrafa do bairro", quando havia eventos e festas, me sentia fazendo parte daquela realidade.

\footnotetext{
${ }^{2}$ A expressão boricua, vem do termo Borinquen, Borikén ou Boriquén, que era o nome que identificava a ilha atribuído pelos índios Tainos. Comumente os porto-riquenhos ainda utilizam o termo boricua para referir-se ao porto-riquenho ou sua cultura.
} 


\section{Narrativa Fotográfica}
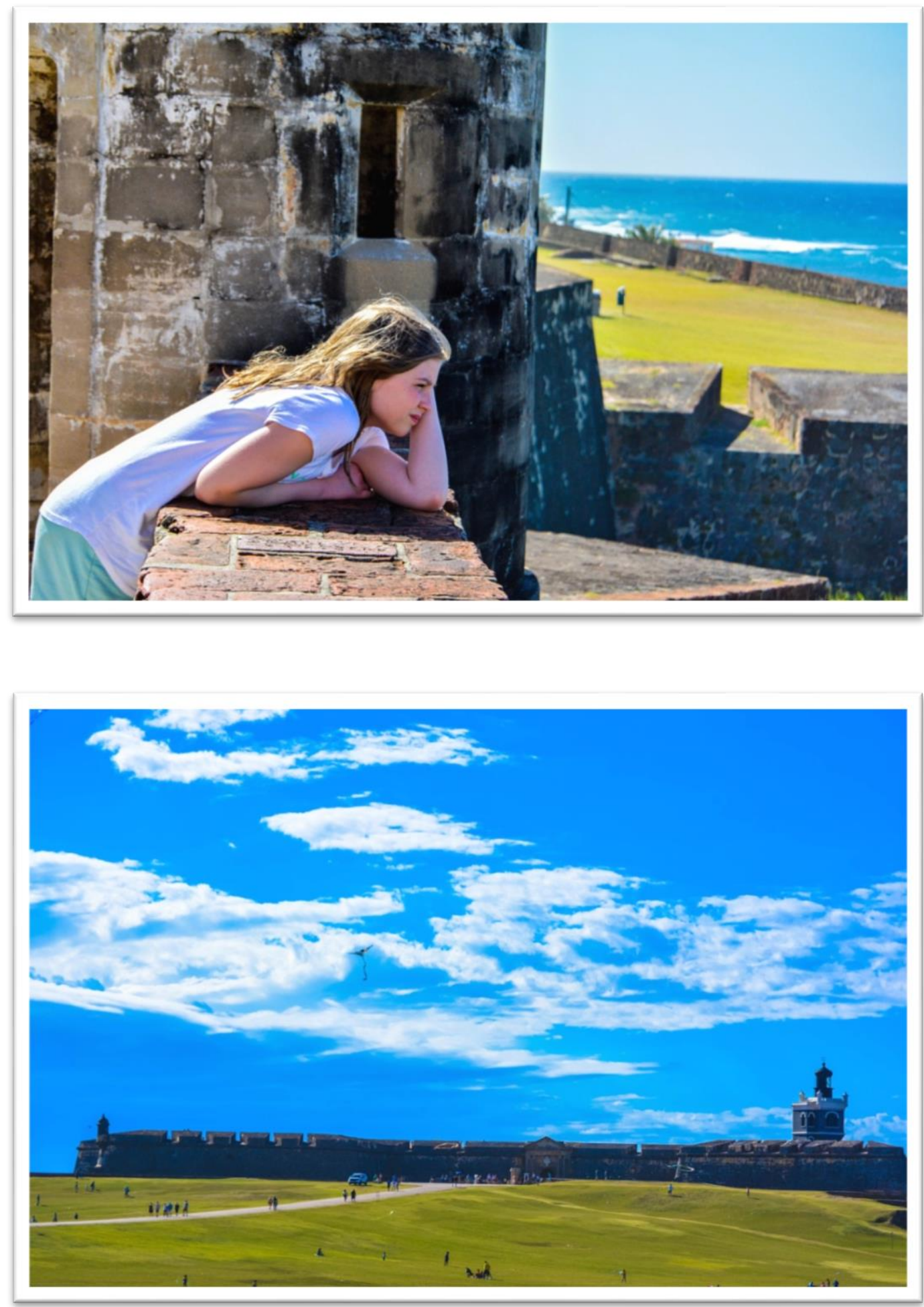

Iluminuras, Porto Alegre, v. 16, n. 40, p. 375-392, ago/dez, 2015. 

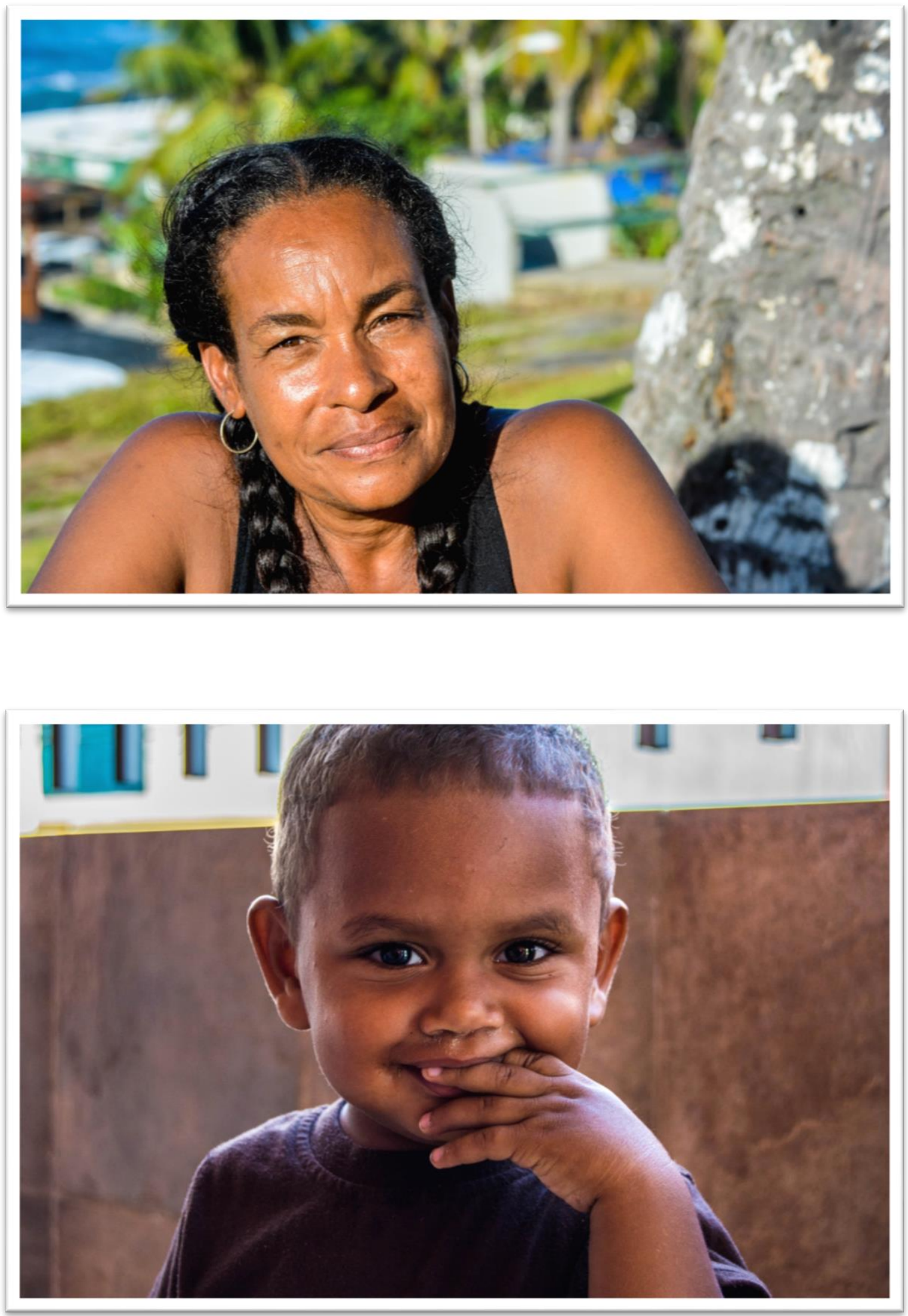

Iluminuras, Porto Alegre, v. 16, n. 40, p. 375-392, ago/dez, 2015. 

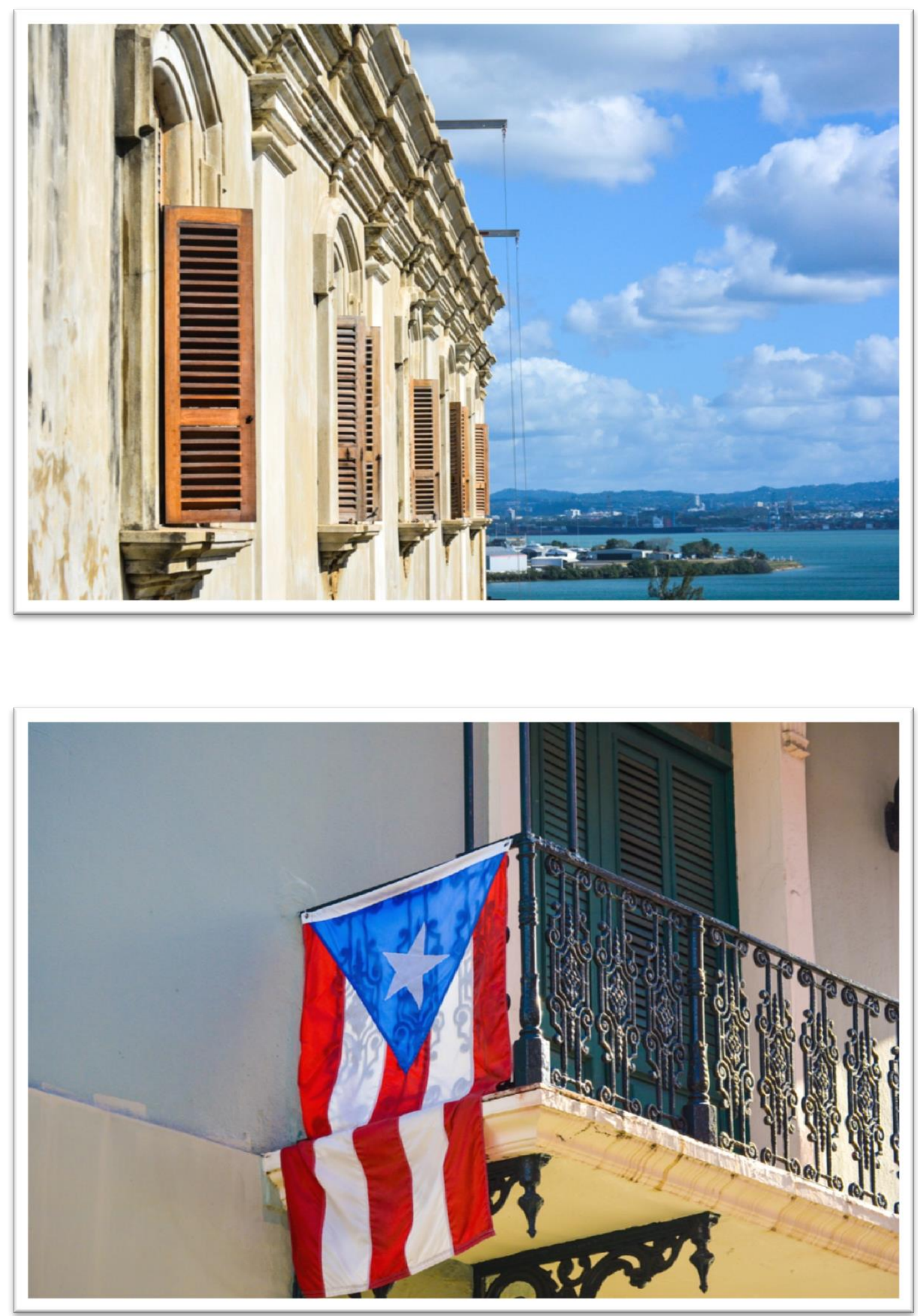

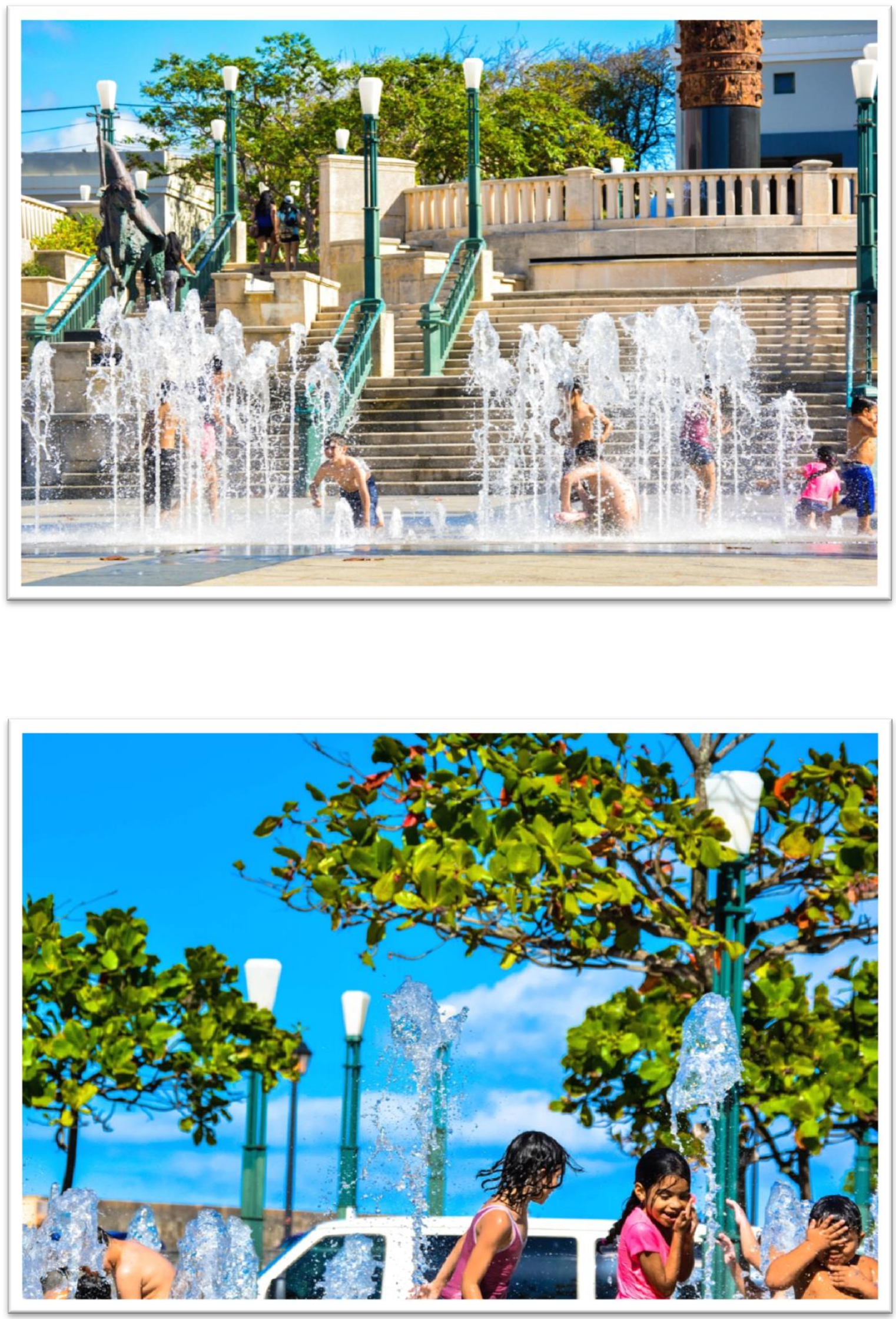

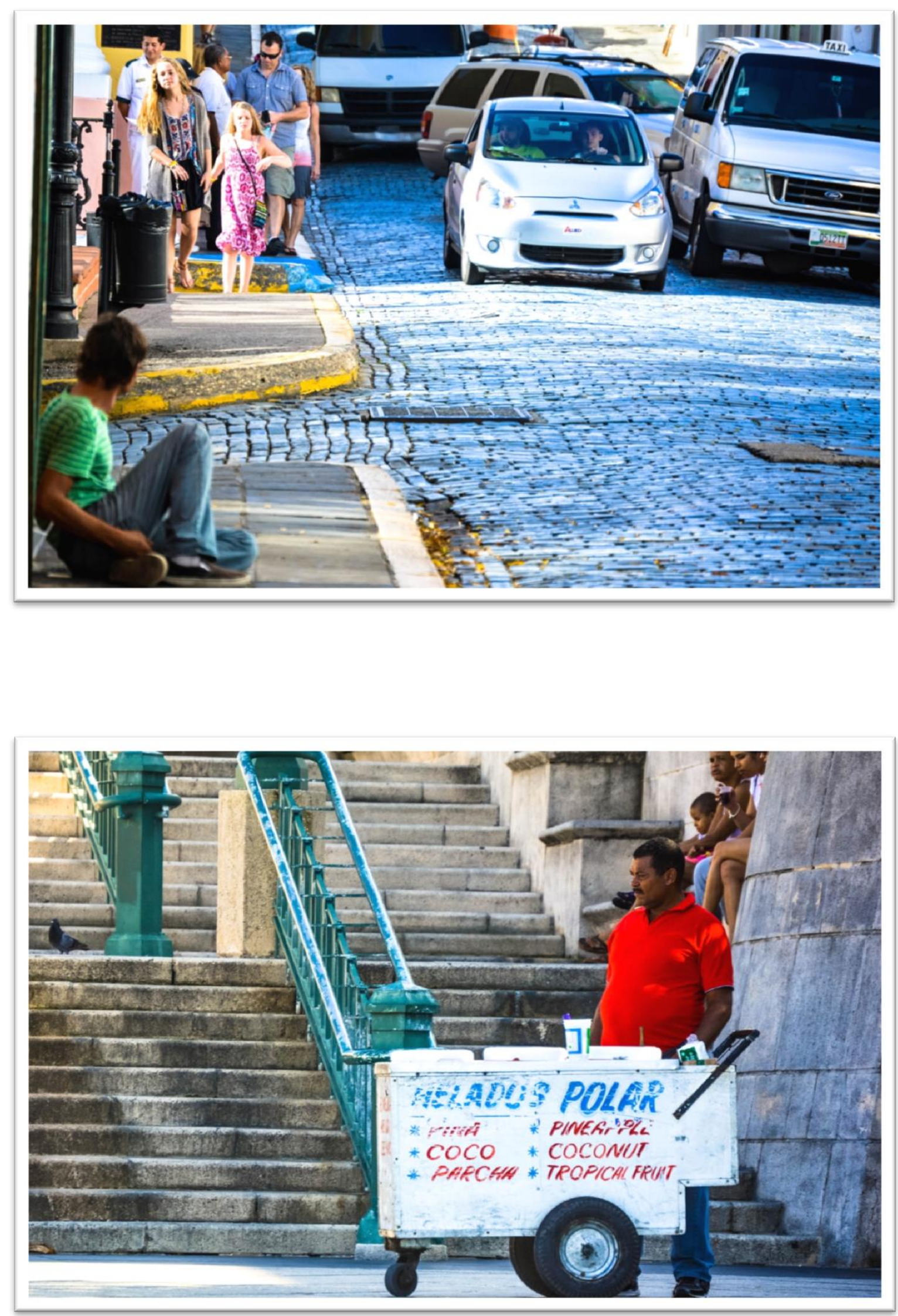

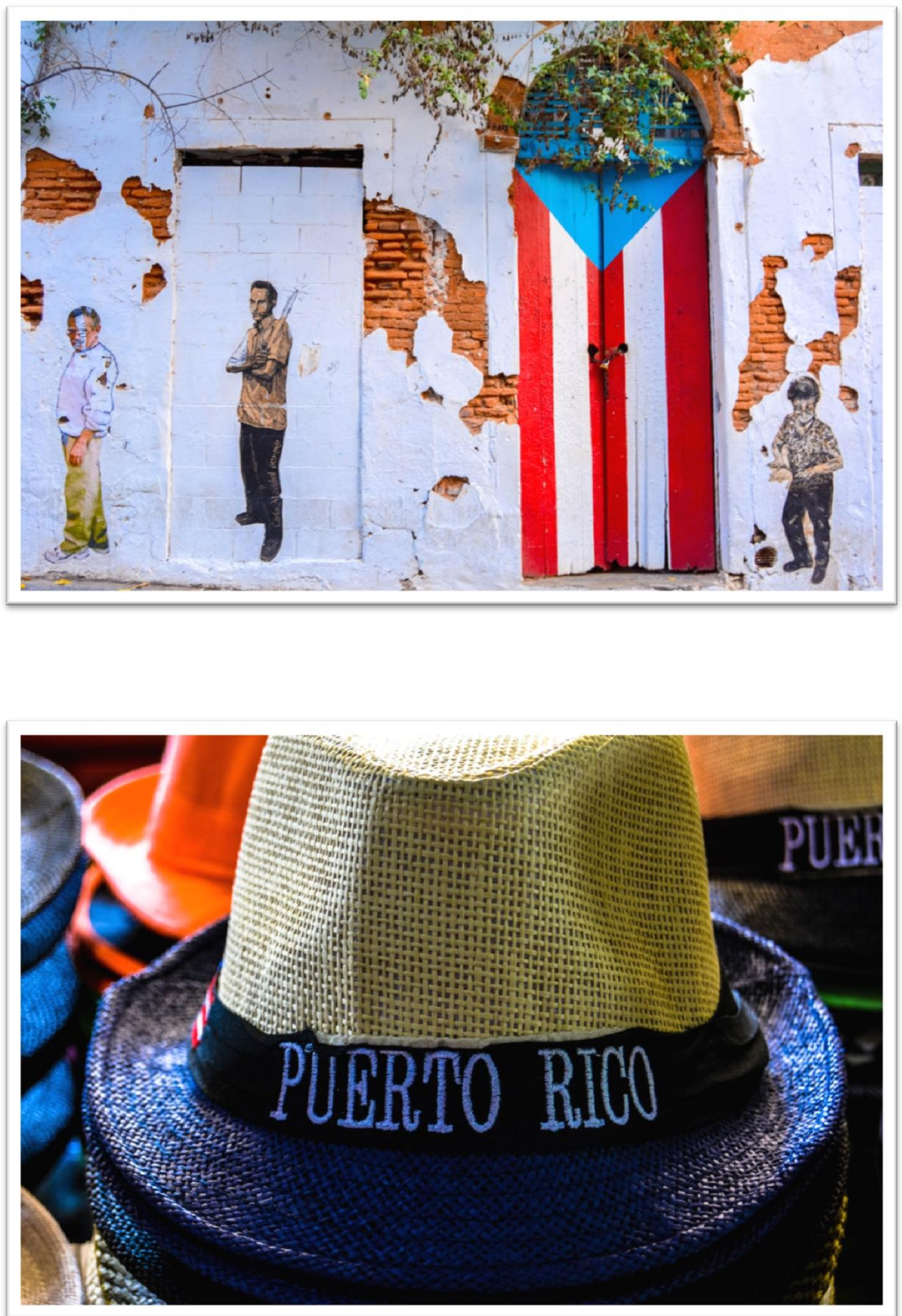

Iluminuras, Porto Alegre, v. 16, n. 40, p. 375-392, ago/dez, 2015. 

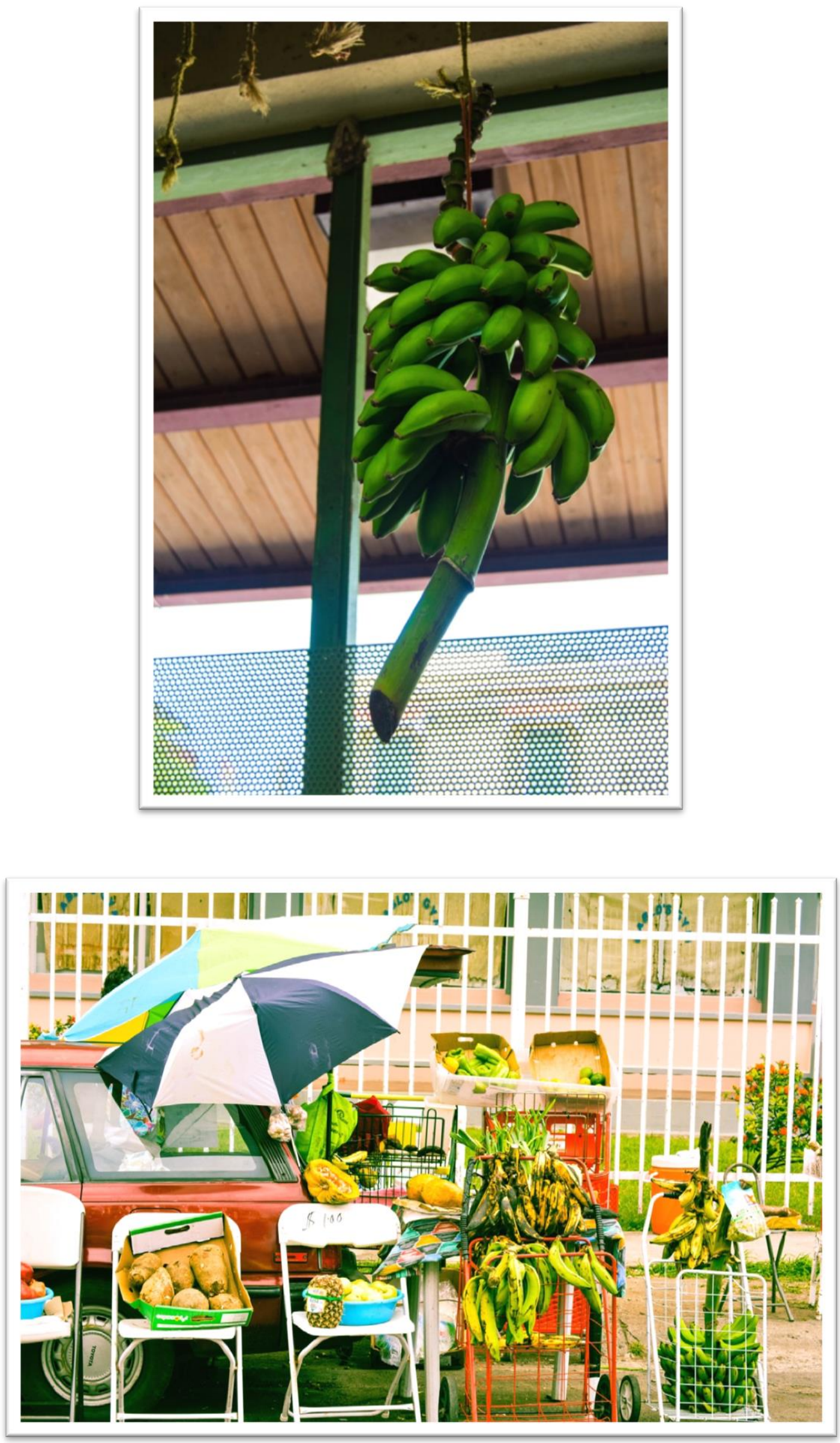

Iluminuras, Porto Alegre, v. 16, n. 40, p. 375-392, ago/dez, 2015. 

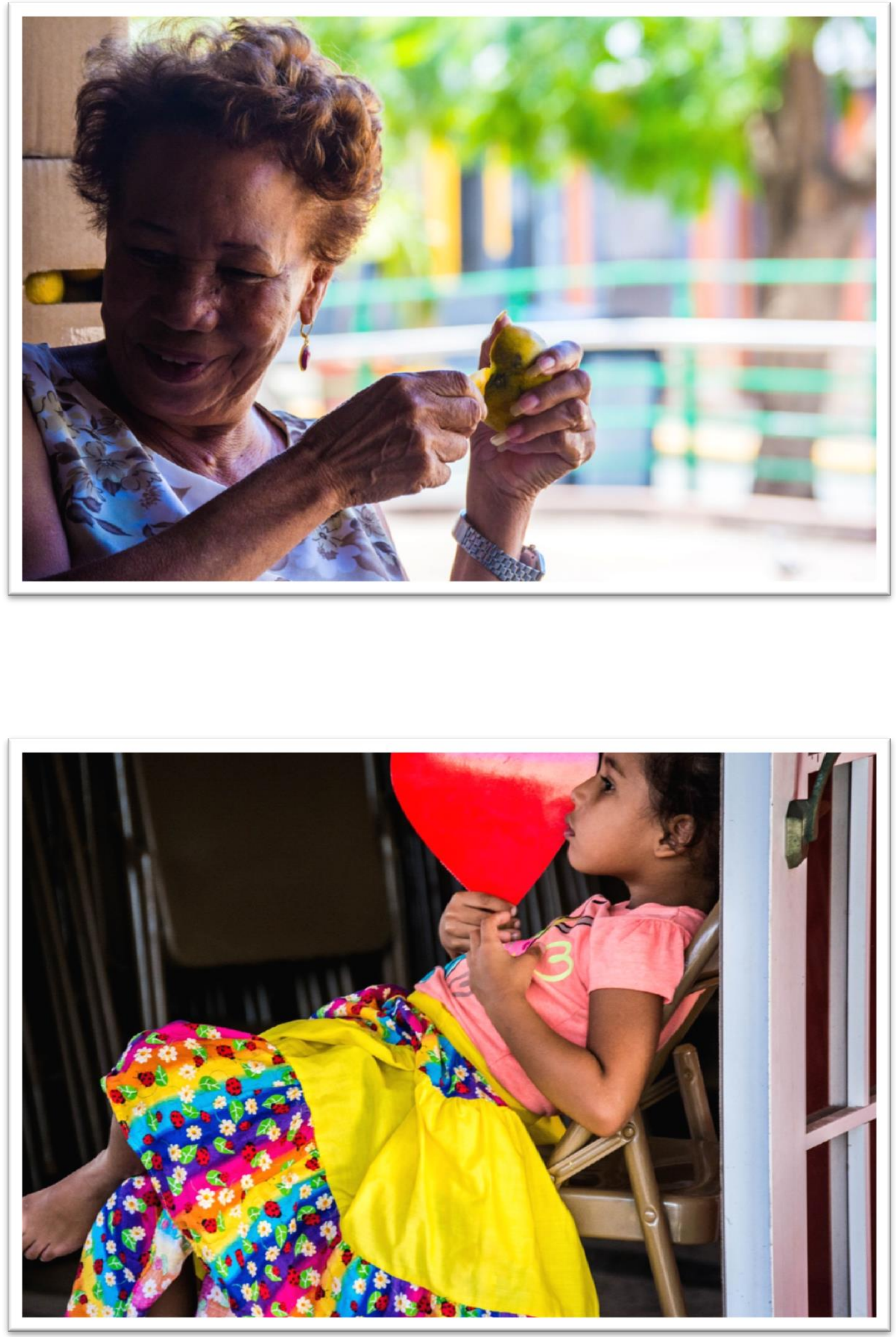

Iluminuras, Porto Alegre, v. 16, n. 40, p. 375-392, ago/dez, 2015. 

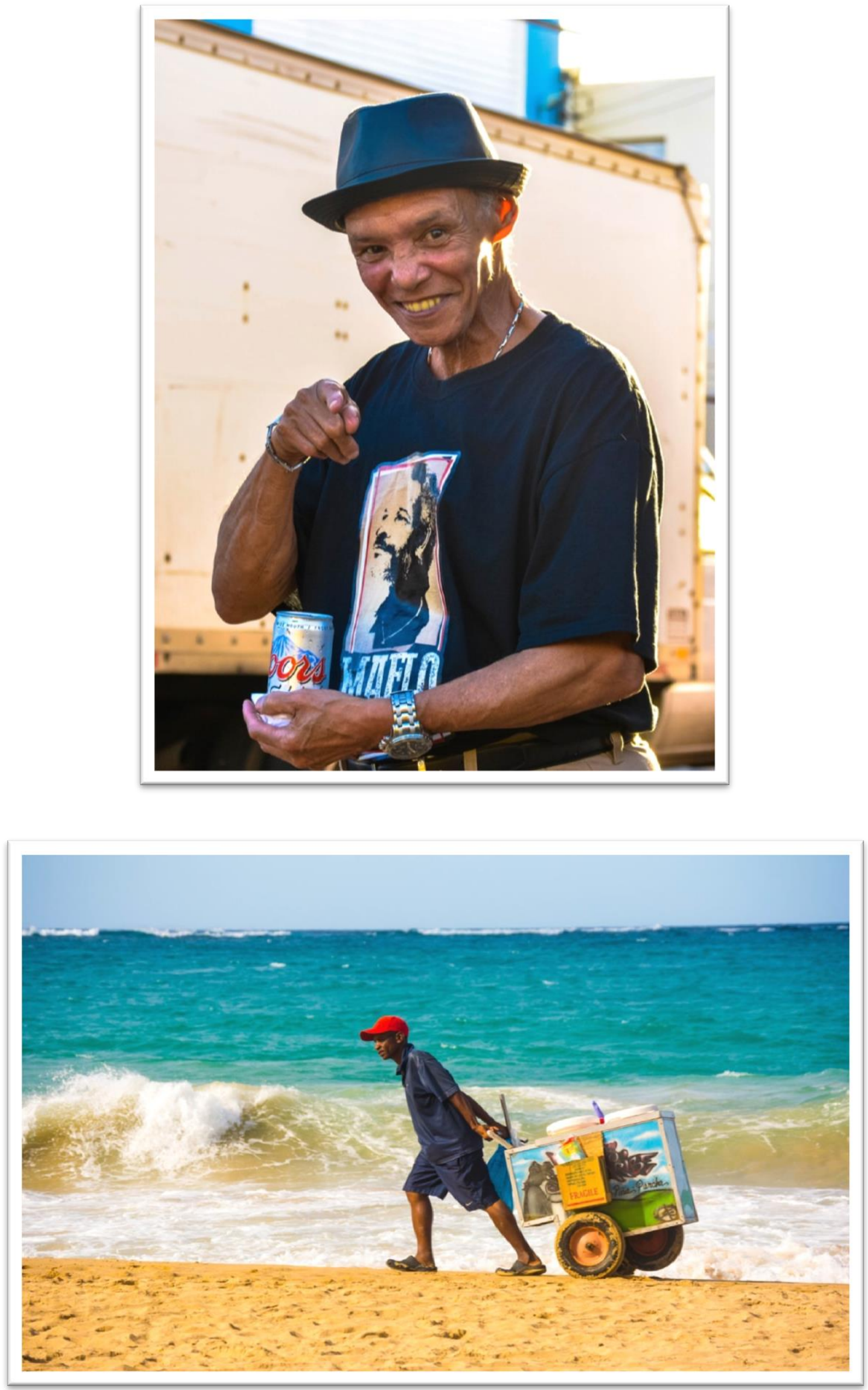

Iluminuras, Porto Alegre, v. 16, n. 40, p. 375-392, ago/dez, 2015. 


\section{Considerações Finais}

Após fazer um retrospecto de como foi minha chegada em Porto Rico, mesmo sendo pela segunda vez, estava em outra cidade em outro momento e se deu de maneira diferente. Tive alguns contratempos iniciais mais "burocráticos" digamos, com a Universidade. Não sabia muito bom onde iria pesquisar nem como, e onde, sabia em linhas gerais o que faria, mas o processo etnográfico muitas vezes nos surpreende, e felizmente foi uma experiência muito importante para minha trajetória.

Sobre a minha vivência, vejo de maneira muito positiva de como os processos foram se desenrolando e como aprendi nos cinco meses que estive imersa na pesquisa. Creio que metodologicamente falando, e dentro desses limites, na inserção etnográfica é muito difícil pensar que com todo pesquisador irá acontecer "tal coisa", ou que exista um "passo a passo" que dirá como o trabalho de campo se desenvolverá. Assim como a fotografia e as técnicas para realizar as mesmas, é somente na prática que vamos absorver essas informações, descobrir e se apropriar de uma maneira muito especifica, singular e particular de cada um. As lentes de cada pesquisador revelarão de maneiras distintas, assim como suas perspectivas e considerações acerca de terminadas temáticas, realidades, sujeitos, etc.

Sendo assim, compartilho da minha vivência com esse ensaio, e espero poder minimamente contribuir e instigar ao exercício de campo, da etnografia, da fotografia (a qual almejo aprender e exercitar mais). Espero poder "dar conta" deste desafio que me propus em utilizar a imagem como outra forma narrativa na minha pesquisa, bem como, conhecer mais do campo da antropologia visual, qual o nosso papel como pesquisador dentre outros questionamentos que sempre "estão em jogo" quando fazemos pesquisa. 


\section{Referências}

ACHUTTI, Luiz Eduardo R. Fotoetnografia. Um estudo de Antropologia Visual sobre o cotidiano, lixo e trabalho. Porto Alegre: Tomo Editorial, Palmarinca, 1997. . Fotoetnografia da Biblioteca Jardim. Porto Alegre: Editora da UFRGS: Tomo Editorial, 2004.

MEAD, Margaret. L'anthropologie visuelle dans une discipline verbale. In: Pour Une Anthropologie Visuelle: Recueil D'articles. Paris: Mouton Éditeur, 1979.

ROCHA, Ana Luiza C. da.; ECKERT, Cornelia. Etnografia de rua: estudo de antropologia urbana. Porto Alegre: UFRGS EDITORA, 2003.

SAMAIN, Etienne. "Ver" e "dizer" na tradição etnográfica: Bronislaw Malinowski e a fotografia. Horizontes Antropológicos, v. 2, p. 23-60. 1995.

Recebido em: 26/10/2015.

Aprovado em: 28/12/2015. 